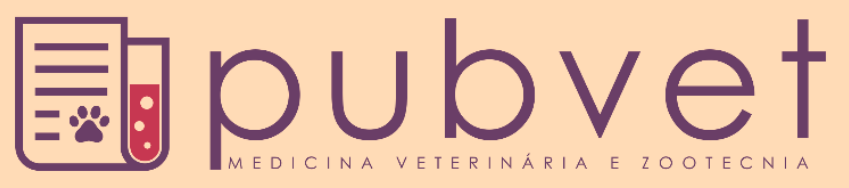

https://doi.org/10.31533/pubvet.v12n11a216.1-4

\title{
Atresia anal tipo III com presença de fístula vaginal e megacólon: Relato de caso
}

\author{
Tairine Melo $\operatorname{Costa}^{1 *}$, Samuel Otemi de Sousa Silva ${ }^{3}$, Thamara Barrozo \\ Sampaio $^{2}$, Daniele Benigno Mota ${ }^{1}$, Vanessa Brígida Pinheiro Rodrigues ${ }^{2}$, Jéssica \\ Maria da Silva Sousa ${ }^{4} \bullet$, Aline Silva $\operatorname{Santos}^{4}{ }^{\bullet}$, Ana Gabriela Pereira Moura Leite ${ }^{4}$ \\ ${ }^{I}$ Médica Veterinária, Residente em Doenças Parasitárias, Universidade Federal do Piauí, Teresina, Piauí, Brasil; \\ ${ }^{2}$ Médica Veterinária, Residente em Clínica e Cirurgia e cães e gatos, Universidade Federal do Piauí, Teresina, Piauí, Brasil; \\ ${ }^{3}$ Médico Veterinário, Residente em Patologia Animal, Universidade Federal do Piauí, Teresina, Piauí, Brasil; \\ ${ }^{4}$ Médica Veterinária autônoma, Teresina, Piauí, Brasil \\ *Autor para correspondência: Hospital Veterinário da Universidade Federal do Piauí - Teresina, Piauí, Brasil. E-mail: tairine_melo@hotmail.com
}

RESUMO: O presente relato de caso tem como objetivo apresentar um caso de atresia anal tipo III, com megacólon e fistula vaginal em cão sem raça definida. A técnica cirúrgica utilizada e a conduta pós cirúrgica com a realização de enemas diários e hidratação foi eficaz na restauração da motilidade normal do intestino. A atresia é pouco frequente na clínica veterinária, e sua principal complicação é impactação colônica devido ao megacólon. No presente caso o paciente apresentou policitemia o que é mais um caso que confirma a presença de policitemia em presença de megacólon.

Palavras chave: atresia, megacolon, policitemia

\section{Type III anal atresia with presence of vaginal fistula and megacolon: Case report}

ABSTRACT. The present case report aims to present a case of type III anal atresia, with megacolon and vaginal fistula in a dog with no defined breed. The surgical technique used and post-surgical management with daily enemas and hydration was effective in restoring normal bowel motility. Atresia is uncommon in the veterinary clinic, and its main complication is colon impaction due to megacolon. In the present case the patient presented polycythemia which is another case that confirms the presence of polycythemia in the presence of megacolon.

Keywords: atresia, megacolon, polycythemia

\section{Atresia anal tipo III con presencia de fístula vaginal y megacolón: Reporte de un caso}

RESUMEN. El presente relato tiene como objetivo presentar un caso de atresia anal tipo III, con megacolon y fistula vaginal en perro un perro criollo. La técnica quirúrgica utilizada y la conducta post quirúrgica con la realización de enemas diarias e hidratación fue eficaz en la restauración de la motilidad normal del intestino. La atresia es poco frecuente en la clínica veterinaria, y su principal complicación es impacto colonico debido al megacolon. En el presente caso el paciente presentó policitemia lo que es otro caso que confirma la presencia de policitemia en presencia de megacolon.

Palabras clave: atresia, megacolon, policitemia 


\section{Introdução}

A atresia anal em cães é considerada rara, porém é mais frequente nesses $(2,1 \%)$ do que em gatos $(1,6 \%)$ e acomete com maior incidência nas fêmeas. A atresia anal é uma alteração anatômica resultante da ausência de comunicação entre o reto e o períneo resultante de defeito congênito, o que resulta na oclusão do reto (Aronson 2007; GarcíaGonzález et al. 2012).

Sua classificação, conforme as alterações anatômicas são divididas em quatro tipos: tipo I os animais apresentam estenose congênita do ânus; tipo II ocorre persistência da membrana anal, e o reto termina em um fundo cego, em um local imediatamente cranial ao ânus imperfurado; tipo III, o ânus também está fechado, porém, a bolsa cega do reto está situada mais cranial do que no observado no tipo II e tipo IV, o reto proximal termina em um fundo cego dentro do canal pélvico, com ânus e reto distais normais (Williams $\underline{\text { \& Niles 2014). }}$.

A apresentação dos sinais clínicos varia de acordo com o tipo de atresia anal. Na do tipo I a ocorrência de sinais como constipação e tenesmo após o desmame e no exame físico da região perineal, observa-se a abertura anal estenosada. Os neonatos com atresia anal do tipo II e IV são clinicamente normais para as primeiras 2 a 4 semanas de vida; em seguida, tornam-se subdesenvolvidos, anoréxicos ou agitados, apresentam dilatação abdominal e defecação ausente, por esta razão pode apresentar megacólon. Para os tipos II e III, pode-se observar uma "marquinha" no local do ânus fechado. Também é possível a apresentação de uma saliência perineal, o que dependerá do nível de atresia anal (Aronson, 2007).
Este relato de caso tem como objetivo apresentar um caso de atresia anal tipo III, com megacólon e fístula vaginal. Como a atresia anal é pouco frequente na clínica médica veterinária este relato visa contribuir para o diagnóstico e tratamento na clínica cirúrgica veterinária.

\section{Relato de caso}

Foi atendido no Hospital Veterinário da Universidade Federal do Piauí Campus Agrícola da Socopo em Teresina - PI (HVU - UFPI) um canino, fêmea, de 16 dias de idade, SRD (Sem Raça Definida) e com peso corporal de 0,3 Kg. O proprietário queixava-se que o animal havia nascido sem ânus há 16 dias e fazia esforço para defecar e não conseguia e há 2 dias haviam começado a sair fezes pela vagina.

Mesmo com essa condição física, alimentavase e urinava normalmente, com dieta exclusivamente a base de leite materno, não sendo a mesma vacinada nem vermifugada. $\mathrm{Na}$ inspeção, verificou-se que o animal não apresentava a abertura do ânus, sendo observado no local uma "marquinha" que demarca o local onde deveria haver a abertura do ânus (Figura 1A), concluindo, portanto, o diagnóstico como atresia anal. Foi solicitado os exames de hemograma, bioquímicos, radiografia e ultrassonografia abdominal.

$\mathrm{Na}$ radiografia foi possível observar a formação de megacólon, este diagnosticado medindo o diâmetro do cólon (A) e dividido pelo comprimento do corpo da sétima vértebra lombar (L7) (Figura 1C). Como o valor obtido foi $>1$, ou seja, o diâmetro do cólon foi maior que o comprimento do corpo da L7, considerou-se a existência de megacólon.

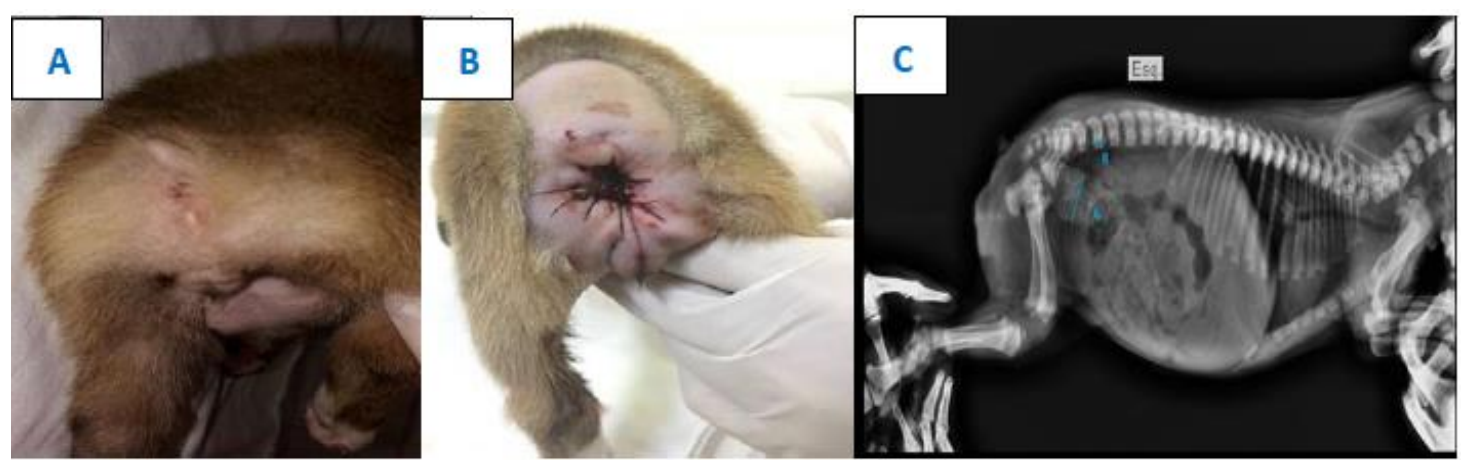

Figura 1. (A)Canino, fêmea, SRD, 16 dias de idade com ânus imperfurado. Observa-se uma "marquinha" no local do ânus fechado. (B) Canino, fêmea, SRD, com suturas simples finalizadas após realização de correção da atresia anal. (C) Radiografia simples. Vista latero-lateral esquerda. Diâmetro do colón (A); Comprimento do corpo da L7 (B). Relação (A/B). Fonte: Arquivo pessoal. 
No exame ultrassonográfico observou-se acúmulo de fezes no colón descendente. Ao avaliar hemograma observou-se uma discreta policitemia, e bioquímicos apresentaram-se dentro da normalidade

Após os resultados dos exames complementares a paciente foi encaminhada para cirurgia. Antes do procedimento cirúrgico, foi recomendado para que o animal permanecesse em um jejum hídrico de 2 horas e alimentar de 6 horas. No procedimento anestésico, foi utilizado como medicação pré-anestésica (MPA) Meperidina (3 $\mathrm{mg} / \mathrm{kg})$, indução com Cetamina $(0,5 \mathrm{mg} / \mathrm{kg})$ e Propofol (3 mg/kg), e manutenção com Isoflurano (vaporizador universal). Além disso, foi realizado bloqueio local através de epidural lombossacral, utilizando-se Lidocaína sem vasoconstritor $(0,25$ $\mathrm{mL} / \mathrm{kg}$ ) e fluidoterapia com $\mathrm{NaCl} 0,9 \%(5 \mathrm{~mL} / \mathrm{kg})$.

A correção cirúrgica iniciou realizando uma incisão em forma de cruz, uma incisão vertical de aproximadamente $1,5 \mathrm{~cm}$ sobre a membrana anal persistente, no local demarcado pela "marquinha". Com o auxílio de uma tesoura romba, o tecido subcutâneo adjacente foi divulsionado até a identificação do fundo cego do reto, que se encontrava cranial ao orifício anal, classicamente como o descrito na atresia anal do tipo III. Foi realizado o pinçamento do saco cego do reto com uma pinça anatômica sem dente de rato, e ancorado com fio de nylon 3 - 0 . Com uma tesoura ponta fina, foi dado um pique no fundo cego. Inseriu-se uma sonda uretral no orifício para avaliar o conteúdo intra-luminal. Comprovou-se que o lúmen continha conteúdo fecal, confirmando que a estrutura tratava-se do reto. $\mathrm{O}$ reto foi tracionado caudalmente, e a junção mucocutânea da abertura incisional foi fixada ao subcutâneo e pele da abertura anal cirúrgica (Figura 1B), utilizando pontos simples separados com fio de nylon 3-0 (Aronson 2007).

Um mês após o procedimento cirúrgico, o animal retornou para atendimento clínico e apresenta-se bem clinicamente, com bom estado nutricional, defecando sem dificuldades. O orifício anal encontrava-se totalmente cicatrizado, sem indício de estenose reto anal e nem constipação (Figura 2).

\section{Discussão}

Assim como descrito por Williams \& Niles (2014) foi diagnosticada a presença da membrana anal, com o ânus imperfurado, e que o reto terminava como uma bolsa cega cranial a abertura fisiológica do reto ainda dentro do canal pélvico. Características que podem ser concludentes que se trata de atresia anal do tipo III. Esse tipo de atresia apresenta todas essas características supracitadas e se difere da do tipo II, pois apresenta bolsa cega ainda mais cranial ao reto.

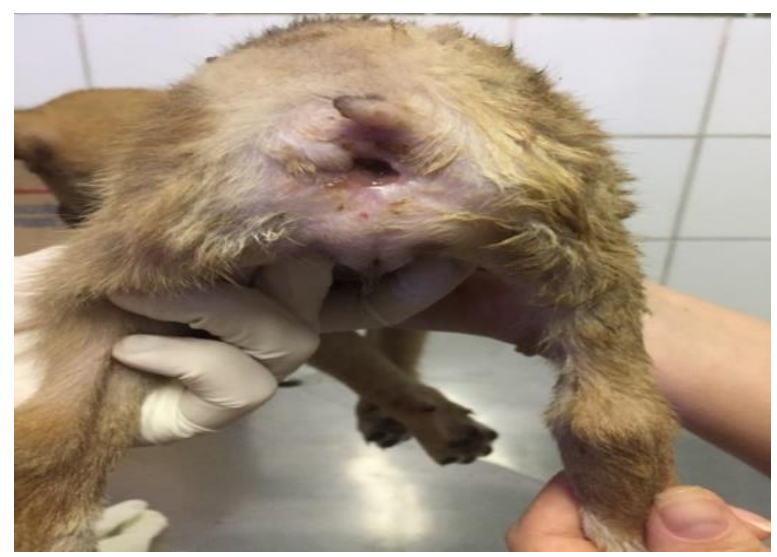

Figura 2. Canino, fêmea, SRD, demonstração do orifício anal um mês após o procedimento cirúrgico de correção da atresia anal.

Os sinais clínicos observados foram: abdômen abaulado com sensibilidade aumentada à palpação abdominal na região hipogástrica, presença de fezes e gases no cólon descendente, ânus imperfurado demarcado por presença de uma "marquinha" no local. Tais achados são condizentes com o relatado por Rahal et al. (2007), Aronson (2007) e Williams \& Niles (2014) que descrevem esses sinais como os principais achados em um paciente com atresia anal do tipo III. Segundo Vianna \& Tobias (2005), na atresia anal, o tratamento cirúrgico é o procedimento de escolha, contudo, podem ocorrer complicações pós-operatórias, incluindo estenose reto-anal, incontinência fecal e atonia do colón secundária à distensão pré-operatória prolongada, sendo que frequentemente a cirurgia é improdutiva e pode necessitar de procedimentos repetidos. Assim como o proposto por Aronson (2007) foi realizado uma incisão vertical sobre a "marquinha" anal e o tecido circunjacente divulsionado até visualização saco cego do reto distal. O mesmo foi ancorado e exteriorizado, sendo suturado junto aos tecidos subcutâneos e pele, utilizando fio monofilamentar. Conforme o descrito por Vianna \& Tobias (2005) e Rahal et al. (2007), a incontinência fecal foi a principal complicação pós-cirúrgica, consequente da impactação colônica e megacólon. Felizmente, diferente do descrito por Machado et al. (2012) e Williams \& Niles (2014) não houve complicações no transcirúrgico, e no pós-cirúrgico. $\mathrm{O}$ animal não apresentou estenose reto anal, embora, nos 
primeiros dias tenha apresentado dificuldades em defecar e constipação, devido à persistência de fezes ressecadas retidas anteriores ao procedimento cirúrgico.

Segundo Thrall (2013) o diâmetro do cólon canino normal deve ser inferior ao comprimento do corpo da vértebra L7. Quando superior, sugerese a ocorrência de megacólon e impacto. $\mathrm{Na}$ radiografia simples da paciente em questão, foi possível observar a ocorrência de megacólon, a relação entre o cólon e o tamanho da vértebra $L 7$, foi bem superior ao padrão normal (A/B igual a $2,48)$.

A principal complicação do megacólon é a hipomotilidade e hipertrofia do colón causando sua impacto. Este pode ser adquirido (fratura pélvica, lesão no nervo pudendo, e complicações de neoplasias) ou congênito (atresia anal). Os sinais incluem letargia, tenesmo, desidratação, anorexia e vomito (Nelson \& Couto 2015). O que confere com os sinais clínicos do paciente que apresentou vômito no primeiro dia pós-cirúrgico.

Assim como descrito por outros relatos o paciente apresentou policitemia o que confirma os achados que policitemia e anemia encontrada em casos de megacólon (Nelson \& Couto 2015). O primeiro tratamento deve ser considerado para o megacólon é o enema por vários dias, hidratação contribui para diminuição da absorção de água pelo colón, e laxante osmótico como a lactulona, no entanto os laxantes emolientes e laxativos estimulantes não são indicados. Dieta de fibra com baixa solubilidade que não exceda $5 \%$ da dieta normal também é indicada (Köster, 2017).

Assim como descrito por Nelson \& Couto (2015) foram prescritos enemas diários, onde houve expulsão das fezes retidas e o animal passou a defecar sem dificuldades, demonstrando que o procedimento cirúrgico pode proporcionar qualidade de vida ao paciente, desde que sejam seguidas as recomendações prescritas no póscirúrgico pelo médico veterinário.

\section{Conclusão}

A atresia anal em cães é pouco frequente na medicina veterinária, no caso descrito o paciente apresentava atresia do tipo III, com presença de fistula vaginal e megacólon. No presente caso se confirmou o relato da presença de policitemia ou anemia em casos de megacólon. A conduta pós cirúrgica foi essencial para melhora do paciente com a realização de enemas diários e hidratação. A técnica cirúrgica se mostrou eficaz e aliado à conduta clínica permitiu a restauração do trânsito intestinal normal do paciente.

\section{Referências}

Aronson L. 2007. Reto e ânus. In: Manual de cirurgia de pequenos animais (ed. by Slatter D). Manole, São Paulo, Brasil.

García-González E.M., Del-Angel-Caraza J., Quijano-Hernández I.A., Marin-Cano G., Barbosa-Mireles M.A. \& IbancovichiCamarillo J.A. 2012. Atresia anal en perros y gatos: conceptos actuales a partir de tres casos clínicos. Archivos de medicina veterinaria 44, 253-260.

Köster, Liza S. 2017. Megacolon in: Chonic Disease management for small animalls. John Wiley \& Sons, p. $205-209$.

Machado C., Silva T.Z., Fernandes C.P.M. \& Nobre M.O. 2012. Fístula reto vaginal associada à atresia anal em cão: relato de caso. Acta Scientiae Veterinariae 40, 34.

Nelson R.W. \& Couto C.G. (2015) Medicina interna de pequenos animais. Elsevier Editora, Amsterdan.

Rahal S.C., Vicente C.S., Mortari A.C., Mamprim M.J. \& Caporalli E.H.G. 2007. Rectovaginal fistula with anal atresia in 5 dogs. The Canadian Veterinary Journal 48, 827-830.

Thrall D.E. 2013. Textbook of veterinary diagnostic radiology. Elsevier Health Sciences, Philadelphia.

Vianna M.L. \& Tobias K.M. (2005) Atresia ani in the dog: a retrospective study. Journal of the American Animal Hospital Association 41, 317-322.

Williams J.M. \& Niles J.D. 2014. BSAVA Manual de cirurgia abdominal em cães e gatos. MedVet, São Paulo, Brasil.

Recebido: 10 Outubro, 2018.

Aprovado: 7 Novembro, 2018.

Publicado: 10 Dezembro, 2018.

Licenciamento: Este artigo é publicado na modalidade Acesso Aberto sob a licença Creative Commons Atribuição 4.0 (CC-BY 4.0), a qual permite uso irrestrito, distribuição, reprodução em qualquer meio, desde que o autor e a fonte sejam devidamente creditados. 